\section{Commentary: Black swan theory or just another bird sighting?}

\author{
C. Huie Lin, MD, ${ }^{a}$ and Michael J. Reardon, $\mathrm{MD}^{\mathrm{b}}$
}

In this issue of the Journal, Sharma and colleagues ${ }^{1}$ from the University of Utah present their experience with surgically removing septal occluder devices for refractory symptoms believed due to nickel allergy. They found an impressive 58 patients in a 10 -year period, with a mean age of 42 years and $95 \%$ of them female. Surveys available for 45 of the patients before the surgical removal of their septal occluder device showed " $58 \%$ rated their quality of life as poor and $69 \%$ were not at all satisfied with their device." Almost all patients had the removal procedure via a small right anterior thoracotomy, and $53(91 \%)$ only required a primary closure after device removal, which suggested that the devices were initially placed in large part for patent foramen ovale (PFO) and not atrial septal defects (ASDs). There were no deaths and little in the way of complications, which one would expect in this younger, healthier population. After surgical removal, all patients reported improved quality of life and $18(42 \%)$ noted complete resolution of symptoms. These are outstanding results for which we congratulate the authors and appreciate their indepth discussion of nickel allergy and potential approaches to this problem. We did, however, find this to be a surprisingly large number from a single center.

As noted in the manuscript, Utah had one interventional cardiologist who placed more than 300 occluder devices per year for this 10 -year period. How this unusually large experience might have influenced the patients drawn into the study and outcomes is unknown to us. With the hundreds of thousands of nitinol-based medical devices implanted every year, the data in the paper, if replicated on a larger scale, would and should cause concern.

From the ${ }^{\mathrm{a} D e p a r t m e n t}$ of Cardiology; ${ }^{\mathrm{b}}$ Department of Cardiothoracic Surgery, Houston Methodist Hospital, Houston, Tex.

Disclosures: Dr Lin reports being a proctor for Abbott/Amplatzer. Dr Reardon has nothing to disclose with regard to commercial support.

Received for publication Nov 3, 2019; revisions received Nov 3, 2019; accepted for publication Nov 5, 2019; available ahead of print Nov 27, 2019.

Address for reprints: Michael J. Reardon, MD, Department of Cardiothoracic Surgery, Houston Methodist Hospital, 6550 Fannin, Suite 1401, Houston, TX 77030 (E-mail: mreardon@ houstonmethodist.org).

J Thorac Cardiovasc Surg 2020;160:510-1

$0022-5223 / \$ 36.00$

Copyright (c) 2019 by The American Association for Thoracic Surgery

https://doi.org/10.1016/j.jtcvs.2019.11.017

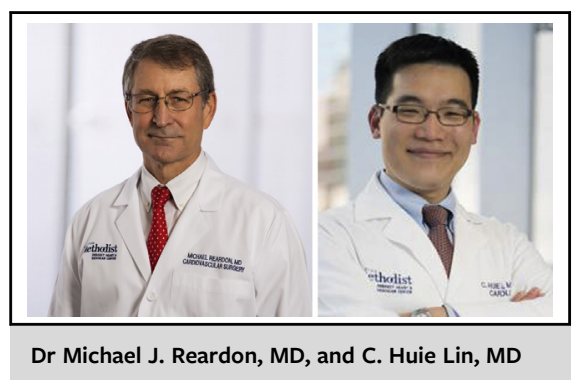

CENTRAL MESSAGE

Nickel allergy exists, but patient selection is very important in avoiding complications.

Nickel is a ubiquitous metal found in both many implanted medical devices as well as everyday products such as jewelry. Cutaneous nickel allergy has long been an extremely common cause of contact dermatitis, present in up to $10 \%$ of women and $2 \%$ of men. The potential for harm from implanted medical devices that contain nickel, however, is less well known and the subject of the current paper. A cluster of symptoms similar to those currently reported have been previously described as "device syndrome" and were thought to be related to nickel allergy. ${ }^{2}$ These authors reported that all symptoms arose within 24 hours, only in patients with a nickel allergy, and abated within a week after treatment with aspirin, clopidogrel, and/or prednisolone. Other studies, however, have shown these symptoms in patients with and without nickel allergy after septal occluder use. ${ }^{3}$ All of the symptoms arose within the first month, and none persisted longer than a year. There was no difference in device function or failure between these groups, and no device had to be surgically removed. The authors noted that a patch test may help identify delayed hypersensitivity but did not predict device function and that a negative skin patch test did not eliminate the risk of acquiring these symptoms. A large retrospective review from 18 US and European centers found that of $13,736 \mathrm{ASD} / \mathrm{PFO}$ closures done over 9 years, only 38 device $(0.28 \%)$ required surgical removal. ${ }^{4} \mathrm{~A}$ variety of reasons for removal were noted, including chest pain (14), residual shunt (12), thrombus (4), pericardial effusion (2), perforation of the atrium or aorta (2), recurrent stroke (1), device endocarditis (1), and unstated reason (2). Of these, only the patients with chest pain or pericardial effusion likely fit the pattern of the current paper $(16 / 13,736$; $0.11 \%$ ). In the patients with device removal for chest pain, only 7 had a nickel allergy. 
One must ask why we cope with these conflicting results? Nickel has been shown to leech from these implanted devices, with serum nickel levels increasing to 5 times normal in the first 6 weeks but returning to normal by 6 months. ${ }^{5}$ Another complicating factor to consider is the disappearance of symptoms with clopidogrel, suggesting a possible platelet embolic source to at least migraine headaches. ${ }^{6}$

In reviewing the present important results, understanding the underlying indication for initial implantation and subsequent surgical device removal is critical: although all patients had a demonstrated cutaneous nickel allergy, the clinical symptoms were more heterogeneous, ranging from fatigue, chest pain, migraine/headache, palpitations, dyspnea, and rash. Of note, the majority of device closures were performed for a documented indication of "migraines" (67\%), whereas 13 closures were performed for various somatic complaints such as "vertigo, fainting, weakness, numbness, and fatigue." To date, there have been no positive randomized-controlled trials demonstrating the efficacy of PFO closure on migraines, ${ }^{7}$ and, as such, it may not be surprising to have patients continue to complain of migraines after device closure. The relationship between the atrial septum and migraines is complex, with at least some component of platelet activity playing a role, ${ }^{8}$ and we have even seen patients with an increase in migraines after surgical ASD repair in our own practice. Even more perplexing is the power of a sham invasive procedure: Patients randomized to sham-control experienced a reduction in migraine days in one PFO closure study. ${ }^{8}$ While few would consider sham thoracotomy ethical, in the ORBITA era, a demand for objective data is mandatory.

Unfortunately, there are no histologic data from the 58 device extractions from which to translate a biologic basis for symptoms or to support an immunologic reaction as the basis for the patients' symptoms. As the authors state, the relationship between patch test reaction to nickel and clinical outcome is not clear. Further, although the in vitro nickel elution characteristics of the Amplatzer device are markedly greater than the GORE HELEX device from that era, ${ }^{4}$ the number of extracted devices is similar $(55 \%$ vs $45 \%$, respectively).

So, what are we to make of the author's central message in this month's Journal article ("Systemic hypersensitivity after implantation of ASD devices in patients with documented nickel allergy are debilitating? Surgical removal resolves symptoms and marked enhances quality of life")? Preprocedure patch testing is not reliable, as they note, and most studies show resolution of symptoms with time, antiplatelets, and anti-inflammatory treatment. We would agree that if significant symptoms persist despite time and medical treatment, surgical removal can and should be discussed with the patient and as seen in this series potentially provides symptomatic relief. However, the number of cases in the current study continues to appear to us to be extremely high compared with the literature and raises the question of why at this site with this group of patients? What would be better than after-the-fact surgical treatment (fully realizing that the current authors did not control the original implant) is careful selection of who receives the treatment in the first place. If what the current authors have found is widely replicated, they have uncovered a surprising, unusual event (need for surgical removal of these devices) of significant importance that we see clearly only in hindsight - a Black Swan Theory. If not validated by others, it may just be the red herring that distracts us from the mote important issue of patient selection.

\section{References}

1. Sharma V, DeShazo RA, Skidmore CR, Glotzbach JP, Koliopoulou A, Javan H, et al. Surgical explantation of atrial septal closure devices for refractory nickel allergy symptoms. J Thorac Cardiovasc Surg. 2020;160:502-9.e1.

2. Rigatelli G, Cardaioli P, Giordan M, Aggio S, Chinaglia M, Braggion G, et al Nickel allergy in interatrial shunt device-based closure patients. Congenit Heart Dis. 2007;2:416-20

3. Kim HJ, Shin JU, Lee J, Lee H, Jin S, Kim SH, et al. Positive reactions to nickel on a patch test do not predict clinical outcome of nickel alloy-based atrial septal defect occluder implantation. Dermatology. 2015;230:184-8.

4. Verma SK, Tobis JM. Explantation of patent foramen ovale closure devices: a multicenter survey. JACC Cardiovasc Interv. 2011;4:579-85.

5. Burian M, Neumann T, Weber M, Brandt R, Geisslinger G, Mitrovic V, et al. Nickel release, a possible indicator for the duration of antiplatelet treatment, from a nickel cardiac device in vivo: a study in patients with atrial septal defects implanted with an Amplatzer occluder. Int J Clin Pharmacol Ther. 2006;44: 107-12.

6. Wertman B, Azarbal B, Riedl M, Tobis J. Adverse events associated with nickel allergy in patients undergoing percutaneous atrial septal defect or patent foramen ovale closure. J Am Coll Cardiol. 2006;47:1226-7.

7. Whisenant B, Reisman M. PFO and migraine: the blind leading the blinded. J Am Coll Cardiol. 2017;70:2775-7.

8. Rodés-Cabau J, Horlick E, Ibrahim R, Cheema AN, Labinaz M, Nadeem N, et al Effect of clopidogrel and aspirin vs aspirin alone on migraine headaches after transcatheter atrial septal defect closure: the CANOA randomized clinical trial. JAMA. 2015;314:2147-54. 